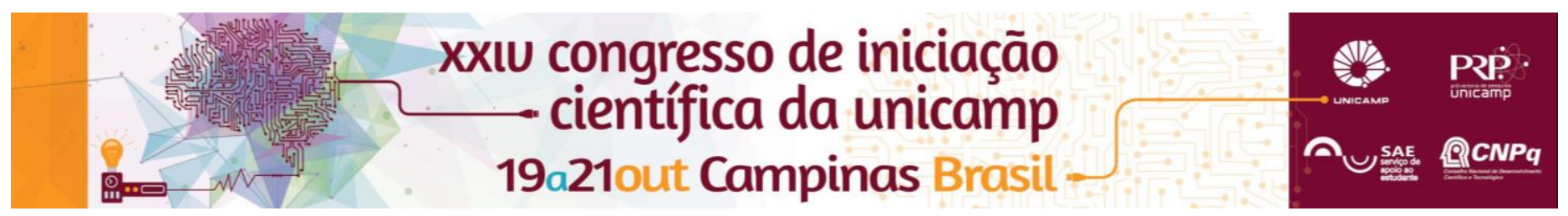

\title{
Levantamento das variáveis que impactam a comunicação no gerenciamento de projetos.
}

\author{
Henrique Perez Nascimento*, Robert Eduardo Cooper Ordoñez
}

\section{Resumo}

Dificuldades relacionadas à má comunicação estão entre os problemas mais comuns e mais impactantes nas organizações - em pesquisas realizadas pelo PMSURVEY.ORG [1] nos anos de 2009 a 2014 abordando os obstáculos mais comuns no gerenciamento de projetos, "problemas de comunicação" aparecia no topo da lista. O impacto da comunicação no contexto de gerenciamento de projetos, no entanto, não é refletido na pesquisa científica, e o conhecimento nessa área ainda se mostra pouco aprofundado. Com o objetivo de contribuir para o desenvolvimento dessa área, este trabalho consistiu no levantamento e definição das variáveis de maior influência na efetividade dos processos de comunicação dentro de um projeto, por meio de pesquisa bibliográfica e consulta com especialistas.

\section{Palavras-chave:}

Gerenciamento de projetos, Comunicação, Barreiras à comunicação.

\section{Introdução}

O estabelecimento de bons processos de comunicação é certamente um dos fatores fundamentais para o sucesso de um projeto. Sendo muitas vezes a principal função de um gerente de projeto, a comunicação é a ponte entre as pessoas e as informações envolvidas, sem a qual não há como uma organização funcionar de forma eficiente.

O estudo da comunicação é muito dificultado, no entanto, pela infinidade de fatores que podem interferir em sua efetividade, chamados de "barreiras à comunicação". E sua enorme complexidade faz com que o controle do gerente sobre todos os parâmetros de influência seja inviável. Dessa forma, faz-se necessária a identificação das variáveis mais importantes para o sucesso ou fracasso de um sistema de comunicação.

O foco deste trabalho foi, portanto, o levantamento e a classificação dessas variáveis de influência, seguidos por uma primeira estimativa das mais importantes.

A pesquisa realizada pode ser classificada como de natureza básica; em relação aos objetivos, pode ser considerada de tipo exploratória e, com relação aos métodos, de caráter indutivo.

Como estratégia de pesquisa, foi feita, inicialmente, uma pesquisa bibliográfica para levantamento de dados. Em um segundo momento, foram feitas análises das informações para identificação de variáveis e, por último, foi feito contato com especialistas para classificar o nível de importância das variáveis identificadas, por meio de entrevista estruturada.

\section{Resultados e Discussão}

A pesquisa bibliográfica permitiu identificar as variáveis de maior influência. Tais variáveis foram separadas em três grupos - em relação à equipe, ao gerente das comunicações e à transmissão das mensagens - e estão listadas a seguir.

\section{Em relação à equipe:}

- Tamanho da equipe;

- Multiculturalidade da equipe;

- Multidisciplinaridade da equipe;

- Integração e confiança da equipe;

- Capacitação dos envolvidos em relação ao meio de transmissão.

\section{Em relação ao gerente das comunicações:}

- Habilidade de comunicação escrita do gerente das comunicações;

- Habilidade de comunicação verbal do gerente das comunicações;

- Habilidade de relacionamento interpessoal do gerente de comunicações;

- Interferências do campo emocional.

\section{Em relação à transmissão das mensagens:}

- Duração do projeto;

- Predominância da comunicação interativa, ativa ou passiva, coerente com a ocasião;

- Adequação do meio de transmissão;

- Mensagens entregues no momento certo;

- Urgência dos processos do projeto;

- Predominância da comunicação verbal ou escrita, coerente com a ocasião;

- Complexidade do mecanismo de comunicação utilizado; - Idiomas envolvidos

Essas 17 variáveis foram levadas, em seguida, a entrevistas com profissionais da área de gerenciamento de projetos, que identificaram as mais relevantes.

\section{Conclusões}

Com a realização das entrevistas, foram identificadas como variáveis mais relevantes: a integração e confiança da equipe, as habilidades de relacionamento verbal e interpessoal do gerente de projetos e o momento correto de entrega das mensagens. As identificadas como menos relevantes foram a multidisciplinaridade da equipe e a duração do projeto.

Além disso, houve maior consenso nas variáveis de integração e confiança da equipe e das habilidades de relacionamento interpessoal e verbal do gerente de projetos, reiterando a importância desses parâmetros.

\section{Agradecimentos}

Os autores agradecem ao CNPq a concessão das bolsas de iniciação científica e aos demais envolvidos com a pesquisa a atenção e dedicação.

${ }^{1}$ PM SURVEY.ORG (2014). Disponível em: www.pmsurvey.org. Acesso em: 15/04/2016. 